\title{
Updates on His Bundle Pacing: The Road More Traveled Lately
}

Fatima M. Ezzeddine MD* \& Gopi Dandamudi MD FHRS ${ }^{\wedge}{ }^{\wedge}$ Krannert Institute of Cardiology, $*$ Indiana University School of Medicine, Indianapolis, IN 46202

COI: FE- none; GD- Consultant and Advisory Board, Medtronic; Advisory Board-Biotronik

Correspondence:

Gopi Dandamudi MD FHRS

Medical Director, IUH Cardiac Electrophysiology

1801 N. Senate Boulevard, Suite 4000 Indianapolis, IN 46202

$\mathrm{Ph}:(317)$ 962-0500

Email: gdandamu@iu.edu

\begin{abstract}
His bundle pacing (HBP) has continued to evolve over the past decade and has started to become a global phenomenon. Evidence is mounting of its clinical benefits as compared to both right ventricular and left ventricular pacing. In this paper, we review recent data in support of His bundle pacing and some of the challenges facing us as we advocate its increasing role in clinical practice.
\end{abstract}

This is the author's manuscript of the article published in final edited form as:

Ezzeddine, F. M., \& Dandamudi, G. (2018). Updates on His bundle pacing: The road more traveled lately. Trends in Cardiovascular Medicine. https://doi.org/10.1016/j.tcm.2018.09.018 


\section{Introduction}

Right ventricular pacing (RVP) has remained as the standard pacing technique globally. However, over the past 2 decades, RVP has been shown to result in deleterious hemodynamic effects including higher rates of atrial fibrillation (AF), heart failure and mortality (DAVID and MOST trials) $(1,2)$. These negative hemodynamic effects result from an abnormal electrical and mechanical activation of the ventricles. In fact, the electrical effects of RVP are similar to those of left bundle branch block (LBBB). To solve this problem of ventricular dyssynchrony, alternative forms of pacing, including biventricular pacing (BiVP) and His bundle pacing (HBP), have emerged. Lately, HBP has started to grow in popularity due to its physiological benefits of recruiting the native His Purkinje system.

\section{Implant success and procedure duration}

The bundle of His is comprised of specialized cardiac muscle fibers that enhance the cardiac conduction properties. It is interspersed within collagen fibers and extends from the compact AV node through the membranous interventricular septum. Both the atrial (non-penetrating) and ventricular (penetrating) portions of the His bundle can be accessed for HBP. Stylet-driven, active fixation leads were used by early investigators to perform HBP. With time, the development of dedicated pacing lead and delivery sheaths has resulted in improved procedural success. A multipolar electrophysiology catheter may be used to locate the His bundle. However, it is not routinely necessary as the His bundle location can be successfully identified in $95 \%$ of the patients without the use of a mapping catheter (3-5).

Recently, a systematic review and meta-analysis on permanent HBP comprising 26 articles demonstrated an overall average implant success rate of $84.8 \%$; it increased to $92.1 \%$ with the use of catheter-delivered systems $(\mathrm{P}<0.001)(6)$. With time and experience, procedural duration has also significantly improved from $3.7 \pm 1.6 \mathrm{hr}$ in 2000 to 80 mins in 2011 to $64 \pm 10$ mins in $2015(4,7,8)$. 


\section{Pacing characteristics and thresholds}

The average His bundle capture thresholds tend to be higher than RVP thresholds due to the inherent anatomical differences between the His bundle and the RV myocardium. Although His bundle capture thresholds are usually higher than RVP thresholds at implant, mean His-bundle capture thresholds remain stable during long-term follow up. Sharma et al. showed stable thresholds after 2 years of followup and Vijayaraman et al. obtained similar findings after 5 years of follow-up $(3,9)$. The development of new dedicated delivery sheaths has also resulted in improved capture thresholds. At this time, only one company has achieved FDA approval for using a specific lead to achieve successful HBP. The 3830 Select Secure MRI SureScan (Medtronic Inc., Minneapolis, USA) is an MRI conditional lead that has a solid core and a $1.8 \mathrm{~mm}$ exposed active helix. Along with the use of dedicated sheaths (a non-deflectable C315His sheath and a deflectable C304His sheath (Medtronic Inc., Minneapolis, USA), HBP implantations has resulted in better pacing thresholds. In a systematic review and meta-analysis on HBP, average pacing thresholds were $1.71 \mathrm{~V}$ at implant and $1.79 \mathrm{~V}$ at $>3$ months follow up (6). Other investigators around the world have used regular pacing leads with shaped stylets and have reported longer term success rates as well (6).

One way to minimize capture thresholds in HBP patients who require cardiac resynchronization devices is to pace using His tip-RV coil pacing configuration rather than traditional bipolar pacing on the HB lead. In patients implanted with ICD/CRT-D, Su et al. showed lower capture thresholds could be obtained using the His-tip RV coil integration $(1.13 \pm 0.51 \mathrm{~V}$ at $0.5 \mathrm{~ms})$ compared with HB unipolar (1.75 $\pm 0.83 \mathrm{~V}$ at $0.5 \mathrm{~ms})$ and $\mathrm{HB}$ tip-ring $(1.59 \pm 0.71 \mathrm{~V}$ at $0.5 \mathrm{~ms})(10)$. $\mathrm{R}$ waves also improved significantly with a His tip-RV coil $(4.28 \pm 2.27 \mathrm{mV})$ compared with $\mathrm{HB}$ unipolar $(3.5 \pm 1.82 \mathrm{mV})$ and HB tip-ring $(2.56 \pm 1.58 \mathrm{mV})(10)$.

Acute His bundle injury current obtained at the time of implantation is associated with better capture thresholds over the long term (4) (figure 1). While obtaining a current of injury is desirable, there may be sites with good pacing threshold and little to no current of injury that remain stable at follow-up. 
The inherent algorithms used at this time are not designed for His bundle pacing and careful attention to the programming algorithms should be undertaken to avoid unintended consequences. One such example was recently published by Padala et al. in a case report describing the auto-capture algorithms of HBP CRT devices in pacing-dependent patients (11). To conserve battery life, RV pacing output can be minimized in non-dependent patients who are achieving LBBB normalization with HBP. However, during atrial and ventricular capture management testing, the device switches to right ventricular-only pacing during ventricular support cycles for the duration of the test and does not pace from the left ventricular port in CRT devices. In patients receiving CRT devices with a His bundle lead in the LV port who are programmed to subthreshold RV outputs, this can lead to disastrous consequences. It is recommended to turn off these automated device tests to avoid ventricular asystole, especially in pacingdependent patients. In all cases of loss of ventricular capture, a thorough device investigation and review of automated device algorithms is always warranted with $\mathrm{HBP}$ at this time. Such issues can be overcome with device algorithms specifically designed with HBP in mind.

\section{Long-term lead performance}

His bundle capture threshold can increase in $\sim 10 \%$ of paced patients during follow-up (12). In most cases, the increase in capture threshold likely results from micro-dislodgement of the His lead. Lead revision may be necessary in $5 \%$ of patients due to progressive increase in thresholds. In this case, a new HBP lead is implanted in a distal location followed by removal of the old lead. The rates of lead dislodgement have improved over time from 17\% (2/12) as reported by Deshmuskh et al. to none as reported by Ajijola in a 2017 study after a median 12 month follow up $(7,13)$. In a more recent study published by Vijayaraman et al. comparing HBP with RVP over 5-year follow-up, HBP was associated with higher rates of lead revisions ( $6.7 \%$ versus $3 \%)$ and generator changes due to premature battery depletion (9\% versus 1\%) (14). In a previous study, Vijayaraman et al. aimed to assess His bundle capture and its effects on LV function during medium to long-term follow up, and to determine His-Purkinje 
conduction (HPC) at the time of generator change in patients with chronic HBP (9). HV intervals remained stable as compared to initial implant ( $44 \pm 4 \mathrm{~ms}$ vs $45 \pm 4 \mathrm{~ms}$ ). During HBP at $700 \mathrm{~ms}, 600 \mathrm{~ms}$, and 500 ms cycle lengths respectively, consistent 1:1 HPC was demonstrated. HBP QRS duration also remained stable during follow-up ( $117 \pm 20 \mathrm{~ms}$ vs $118 \pm 23 \mathrm{~ms})$. HBP thresholds at implant and generator change were $1.9 \pm 1.1 \mathrm{~V}$ and $2.5 \pm 1.2 \mathrm{~V}$ at $0.5 \mathrm{~ms}$ respectively. Despite high pacing burden $(77 \pm 13 \%)$, there was no deterioration in LVEF during follow up (50 $\pm 14 \%$ at implant vs $55 \pm 6 \%$ at follow up; $\mathrm{P}=0.06$ ). As such, HBP was shown not to cause new HPC abnormalities. Battery longevity was longer in this series of patients with HBP because back-up RV lead was not routinely used which limited battery depletion. Even in patients with intra-His block, distal His-Purkinje conduction was preserved in patients paced with HBP.

\section{Selective versus Non-Selective HBP}

Selective HBP (SHBP) is achieved by placing the pacing lead deep into the His bundle resulting in His bundle capture only (figure 2). It is defined as ventricular activation occurring exclusively via HisPurkinje system as evidenced by a QRS morphology being identical to baseline (if normal) and complete recruitment of bundle branch blocks in patients with baseline bundle branch blocks. In these patients, there is an isoelectric segment between the pacing spike and QRS complex which is equal to the intrinsic HV delay in most cases. Nonselective HBP (NSHBP) is achieved when there is a significant amount of myocardium surrounding the His bundle where pacing always results in fusion between HPC and local myocardial capture (figure 3). In these patients, there is no isoelectric interval between the pacing stimulus and QRS onset. A pseudo-delta wave is seen instead of an isoelectric line representing the septal myocardial activation fusing with the His-Purkinje activation. Zhang et al. conducted a study assessing the acute effect of SHBP, NSHBP and right ventricular septal pacing (RVSP) on electrical synchrony and LV mechanical synchrony using electrocardiogram and phase analysis of gated single photon emission computed tomography (SPECT) myocardial perfusion imaging (MPI) (15). HBP was performed in thirty- 
seven patients: SHBP in 23 patients and NSHBP in 14 patients. Thirty-one patients simultaneously underwent back up RVSP. The paced QRS duration $\left(\mathrm{QRS}_{\mathrm{d}}\right)$ in the SHBP low- and high-output mode and in the NSHBP high-output mode were similar to the baseline intrinsic $\mathrm{QRS}_{\mathrm{d}}$. QRS duration in the NSHP low-output mode was slightly longer than the baseline. SHBP and high-output NSHBP were shown to have better electrical and mechanical synchrony than RVSP (15).

\section{His bundle pacing vs. right ventricular pacing}

Several small studies have compared HBP with RVP and showed that HBP resulted in improved exercise tolerance, New York Heart Association (NYHA) functional class, left ventricular ejection fraction (LVEF), and mitral and tricuspid regurgitation (table A). Recently, Vijayaraman et al. published their 5-year follow up results comparing HBP to RVP and found that HBP is associated with reduction in death or heart failure hospitalization (HFH) during long-term follow up as compared to RVP patients with $>40 \%$ ventricular pacing ( $32 \%$ vs $53 \%$; hazard ratio $1.9 ; \mathrm{P}=0.04)(14)$. This study also demonstrated that pacing-induced cardiomyopathy was significantly lower in HBP compared to RVP patients (2\% vs $22 \%$; $\mathrm{P}=0.04)$. This reduction in the primary outcome associated with HBP may be explained by several factors including reduction in heart failure resulting from elimination of ventricular dyssynchrony, QRS narrowing and reduction in $\mathrm{T}$ peak to $\mathrm{T}$ end duration which is associated with increased risk of arrhythmias. Similarly, Abdelrahman et al. published a study comparing the clinical outcomes of HBP to RVP from the Geisinger HBP registry (16). HBP was successful in $92 \%$ of the patients in whom it was performed. The primary endpoint of death, HFH, or upgrade to BiVP was significantly lower in the HBP group ( 83 of 332 patients [25\%]) compared to RVP (137 of 433 patients [32\%]; hazard ratio [HR]: 0.71; 95\% confidence interval $[\mathrm{CI}]: 0.534$ to $0.944 ; \mathrm{p}=0.02$ ). This difference was observed primarily in patients with ventricular pacing > 20\% (25\% in HBP vs. $36 \%$ in RVP; HR: 0.65 ; $95 \%$ CI: 0.456 to 0.927 ; $\mathrm{p}=0.02)$. The incidence of HFH was significantly reduced in the HBP group (12.4\% vs. $17.6 \%$; HR: $0.63 ; 95 \%$ CI: 0.430 to $0.931 ; p=0.02)$. A trend toward reduced mortality was noted with HBP $(17.2 \%$ 
vs. $21.4 \%$, respectively; $\mathrm{p}=0.06$ ). Among patients with ventricular pacing burden $\leq 20 \%$, the primary outcome was similar in the HBP and RVP groups ( $22 \%$ vs $23.7 \%$, respectively; $\mathrm{p}=0.34$ ). Patients in the RVP group with baseline LVEF $<50 \%$ had significantly increased risk for reaching the primary endpoint (HR: 1.785 ; 95\% confidence interval [CI]: 1.054 to 3.023 ; $\mathrm{p}=0.03$ ) compared to patients with LVEF > $50 \%$. This was not found in the HBP group when data were stratified according to LVEF. Another study supporting the beneficial effects of HBP in pacing dependent patients irrespective of the EF was published by Ye et al. (17). This study assessed the feasibility and intermediate follow-up results of upgrade to HBP in patients with long term RVP referred for pulse generator change. HBP was successful in $85.7 \%(12 / 14)$ of the patients in whom it was attempted. Nine patients had an $\mathrm{EF} \geq 40 \%$ and underwent upgrade to $\mathrm{HBP}$ whereas three patients had an $\mathrm{EF}<40 \%$ and underwent $\mathrm{HBP}$ and $\mathrm{BiVP}$ as well with coronary sinus lead placement. $\mathrm{QRS}_{\mathrm{d}}$ was significantly reduced post-HBP implantation from $157.8 \pm 13.3$ ms to $109.3 \pm 16.9 \mathrm{~ms}(\mathrm{p}<0.001)$. After 6 months follow-up, NYHA functional status significantly improved from $2.7 \pm 0.6$ to $1.8 \pm 0.6(\mathrm{p}=0.007)$ and left ventricular internal diastolic diameter (LVIDd) was significantly reduced from $5.5 \pm 0.4 \mathrm{~cm}$ to $5.3 \pm 0.3 \mathrm{~cm}(\mathrm{p}=0.03)$. HBP improved HF symptoms in pacing dependent patients with preserved EF who previously had RVP. They concluded that HBP appears to be safe and feasible for upgrade in patients with long term RVP regardless of the LVEF. Another recent study was performed by Shan et al. to assess the clinical outcomes of upgrading to permanent HBP in patients with heart failure who underwent device upgrade from RVP (18). They demonstrated that in chronically paced patients with pacing induced cardiomyopathy (LVEF<50\%), upgrade to HBP resulted in significant improvement in QRS duration and LVEF (from 36.1\% $\pm 8.9 \%$ to $53.6 \% \pm 10.3 \%$ at 1 year follow up; $\mathrm{P}<0.01$ ). Other findings after HBP upgrade included improvement in mitral valve regurgitation, serum brain natriuretic peptide (BNP) concentrations, cardiothoracic ratios, and NYHA functional status $(\mathrm{P}<0.01$ for all). Despite all these beneficial results, randomized controlled clinical trials comparing HBP with RVP are still lacking and are needed to further validate these findings. 


\section{HBP for cardiac resynchronization therapy (CRT) and bundle branch blocks}

The concept of longitudinal dissociation of the His bundle has been postulated many decades ago. According to this concept, predestined fibers to the bundle branches are present within the proximal portions of the common His bundle and bundle branch blocks may be a manifestation of focal impulse blocks within the proximal portions of the common bundle. In such cases, HBP can overcome the block by pacing distal to the site of block resulting in a narrow QRS morphology (figure 3). Narula et al. first reported the normalization of BBB by distal HBP in the 1970s (19). Sharma et al. described two cases of left bundle branch delay with evidence of split His electrogram during unipolar mapping from the tip of the His bundle lead during pacemaker implantation (20). Pacing at these sites resulted in complete recruitment of the LBBB. CRT via BiVP is indicated in patients with severely reduced ejection fraction and wide bundle branch block. However, one third of these patients do not respond to conventional CRT $(21,22)$. Permanent atrial fibrillation is one of the reasons for not responding to CRT (23) . Lack of response to CRT was also seen in patients with normal QRS and those with right bundle branch block (RBBB). Indeed, the largest group of non-responders were HF patients with QRS duration $<130 \mathrm{msec}$ $(24,25)$. In these patients, BiVP was associated with higher mortality incidence $(26,27)$. In patients with atrioventricular block and systolic dysfunction, equivocal results were demonstrated in two clinical trials $(28,29)$. Furthermore, some patients have anatomical obstacles that hinder LV lead placement, including suboptimal coronary sinus venous branches and phrenic nerve stimulation. As such, CRT via BiVP fails to meet the needs of a significant group of patients and alternative pacing techniques are highly desired.

There are limited data on HBP as an alternative to BiVP for CRT. From a speculative point of view, in contrast to the non-physiologic BiVP in which ventricular activation occurs in response to RV endocardial and LV epicardial pacing, physiologic ventricular activation by activating previously dormant His-Purkinje tissue via HBP seems to be promising. In a crossover design trial, Lustgarten et. al was able to demonstrate successful recruitment of bundle branch blocks with His bundle pacing (46). They were also able to demonstrate improvement in clinical outcomes that were similar between His bundle pacing 
and LV pacing. Several prospective cohort studies compared HBP to BiVP for CRT in patients with AV nodal block, patients who failed coronary sinus lead placement and others with lack of response to conventional CRT. The results of these studies were promising and demonstrated improvement in QRS duration, LVEF and NYHA functional status in patients with HBP (30) (table 2). The largest of these studies was a multicenter study by Sharma et al. (31). The study assessed HBP for CRT in CRT-eligible patients and BiVP non-responders. It demonstrated a 90\% success rate with significant narrowing of QRS from $157 \pm 33 \mathrm{~ms}$ to $117 \pm 18 \mathrm{~ms}(\mathrm{P}=.0001)$, increase in LVEF from $30 \% \pm 10 \%$ to $43 \% \pm 13 \%$ $(\mathrm{P}=.0001)$, and improvement in NYHA functional class from $2.8 \pm 0.5$ to $1.8 \pm 0.6(\mathrm{P}=.0001)$ with HBP (31). Recently, Huang et al. published a study assessing the efficacy of HBP/in correcting LBBB and its clinical outcomes in patients with LBBB and HF (32). They showed that HBP acutely corrected LBBB in 72 of 74 patients (97.3\%). Thirty patients completed 3-year follow-up with LVEF increasing from a baseline of $32.4 \pm 8.9 \%$ to $55.9 \pm 10.7 \%$ ( $\mathrm{p}<0.001$ ), LVESV decreasing from a $137.9 \pm 64.1 \mathrm{~mL}$ to $52.4 \pm 32.6 \mathrm{~mL}(\mathrm{p}<0.001)$ and NYHA Class improving from $2.73 \pm 0.58$ to $1.03 \pm 0.18(\mathrm{p}<0.001)(32)$. The clinical feasibility and efficacy of HBP was also studied in patients with RBBB and HF by Sharma et al. (33). HBP was successful in 37 of 39 patients (95\%) with narrowing of RBBB in 78\% cases. During a mean follow-up of $15 \pm 23$ months, HBP resulted in a significant narrowing of QRS from $158 \pm 24$ to $127 \pm 17 \mathrm{~ms}(\mathrm{P}=0.0001)$, increase in LVEF from $31 \pm 10 \%$ to $39 \pm 13 \%(\mathrm{P}=0.004)$, and improvement in NYHA functional class from $2.8 \pm 0.6$ to $2 \pm 0.7$ ( $\mathrm{P}=0.0001$ ) (33). Furthermore, Shan et al. demonstrated that in CRT non-responders, upgrade to HBP significantly reduced $\mathrm{QRS}_{\mathrm{d}}$ and improved LVEF (from $34.6 \% \pm 5.7 \%$ to $51.1 \% \pm 8.5 \%$ at 1 year follow up; $\mathrm{P}<0.01)(18)$. However, none of these studies is a randomized controlled clinical trial with head-to-head comparison between HBP and BiVP. At this time, HBP is reserved for patients who are CRT non-responders, who have failed coronary sinus lead placement or patients with atrioventricular (AV) node disease requiring atrioventricular node ablation (AVNA). It should also be attempted in patients with anatomical challenges before considering surgical epicardial LV lead placement. Randomized controlled clinical trials comparing HBP with BiVP are 
underway to better assess the efficacy of HBP in CRT (His-SYNC, HOPE-HF, and NCT02805465) (3436).

Recently, the concept of trans-septal pacing with direct stimulation of the left bundle branch (LBB) fascicles has been entertained and demonstrated by a few clinical investigators (figure 4). It is possible to place a RV lead deep in the septum to try to capture the LBB fascicles directly. This may be a viable approach in the long run as the pacing thresholds seem to be significantly lower than direct His bundle pacing. This novel strategy was reported to correct LBBB with a low and stable output (37). More evidence is needed to confirm safety and long term efficacy of this approach.

\section{His bundle pacing \& Atrioventricular nodal ablation (AVNA)}

Chronic AF with rapid ventricular rates where adequate rate control cannot be achieved pharmacologically can result in dilated cardiomyopathy and HF. Several small prospective studies compared chronic BiVP to RVP in patients undergoing ablation of the AV node for management of AF with rapid ventricular rates. These trials showed better clinical outcomes (NYHA functional status, quality of life, LVEF) with BiVP as compared to RVP. In patients undergoing AVNA, HBP can also be beneficial (figure 2). In fact, early studies of HBP were reported in patients with AF undergoing AVNA. A recent study by Huang et al. included 52 heart failure patients with narrow QRS who underwent AVNA for AF (38) . Compared to baseline, HBP significantly improved LVEF, left ventricular end diastolic pressure (LVEDP), and NYHA functional status. These benefits were more noticeable in patients with depressed LVEF. Similarly, Vijayaraman et al. studied the feasibility and safety of HBP in patients undergoing AVNA and its effect on LVEF (39). AVNA and HBP were successful in 95\% of patients. Final HBP thresholds at implant was $1 \pm 0.8 \mathrm{~V}$ at $1 \mathrm{~ms}$ and increased to $1.6 \pm 1.2 \mathrm{~V}$ at $1 \mathrm{~ms}$ during a mean follow-up of $19 \pm 14$ months. Left ventricular ejection fraction increased from $43 \pm 13 \%$ to $50 \pm 11 \%$ $(\mathrm{P}=0.01)$. NYHA functional status improved from $2.5 \pm 0.5$ to $1.9 \pm 0.5(\mathrm{P}=0.04)$. HBP seems to be ideally suited to this population if AVNA can be safely performed at the time of implant without increasing the pacing thresholds. 


\section{Conclusion}

Recently, there has been mounting evidence supporting the role of HBP in various clinical settings. Studies have shown that HBP can be successfully utilized in almost all clinical scenarios, including RV pacing induced cardiomyopathy, AV nodal and infra-nodal heart blocks, AVNA for supraventricular arrhythmias, chronic bundle branch corrections in lieu of LV lead placement and prophylactically in patients who require permanent ventricular pacing. In all these subsets of patients, HBP has shown the ability to correct ventricular dyssynchrony and to improve outcomes. The allure of HBP lies in the fact that the intrinsic conduction system can be recruited and function as nature intended. Such claims cannot be made by both RV and LV pacing and account for their detrimental and limited benefits, respectively. However, lack of investments to develop better tools, leads and devices has resulted in slower progress. Large scale randomized trials and concomitant investments need to be undertaken to move the field forward and make HBP a permanent reality in the vast majority of patients who require ventricular pacing.

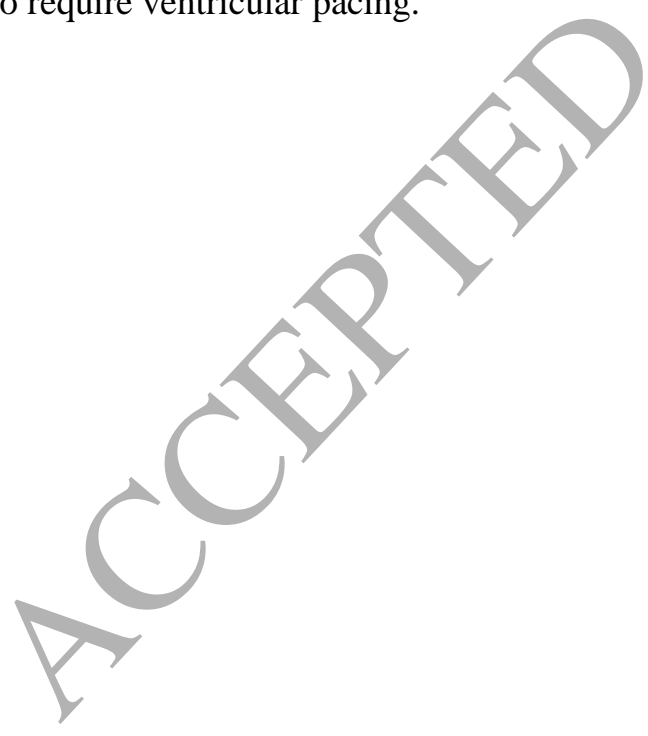




\section{References:}

1. Sweeney MO, Hellkamp AS, Ellenbogen KA, Greenspon AJ, Freedman RA, Lee KL, et al. Adverse effect of ventricular pacing on heart failure and atrial fibrillation among patients with normal baseline QRS duration in a clinical trial of pacemaker therapy for sinus node dysfunction. Circulation. 2003;107(23):2932-7.

2. Wilkoff BL, Cook JR, Epstein AE, Greene HL, Hallstrom AP, Hsia H, et al. Dual-chamber pacing or ventricular backup pacing in patients with an implantable defibrillator: the Dual Chamber and VVI Implantable Defibrillator (DAVID) Trial. JAMA. 2002;288(24):3115-23.

3. Sharma PS, Dandamudi G, Naperkowski A, Oren JW, Storm RH, Ellenbogen KA, et al. Permanent His-bundle pacing is feasible, safe, and superior to right ventricular pacing in routine clinical practice. Heart Rhythm. 2015;12(2):305-12.

4. Vijayaraman P, Dandamudi G, Worsnick S, Ellenbogen KA. Acute His-Bundle Injury Current during Permanent His-Bundle Pacing Predicts Excellent Pacing Outcomes. Pacing Clin Electrophysiol. 2015;38(5):540-6.

5. Vijayaraman P, Naperkowski A, Ellenbogen KA, Dandamudi G. Electrophysiologic Insights Into Site of Atrioventricular Block: Lessons From Permanent His Bundle Pacing. JACC Clin Electrophysiol. 2015;1(6):571-81.

6. Zanon F, Ellenbogen KA, Dandamudi G, Sharma PS, Huang W, Lustgarten DL, et al. Permanent His-bundle pacing: a systematic literature review and meta-analysis. Europace. 2018.

7. Deshmukh P, Casavant DA, Romanyshyn M, Anderson K. Permanent, direct His-bundle pacing: a novel approach to cardiac pacing in patients with normal His-Purkinje activation. Circulation. 2000;101(8):869-77.

8. Zanon F, Svetlich C, Occhetta E, Catanzariti D, Cantu F, Padeletti L, et al. Safety and performance of a system specifically designed for selective site pacing. Pacing Clin Electrophysiol. 2011;34(3):339-47. 9. Vijayaraman P, Dandamudi G, Lustgarten D, Ellenbogen KA. Permanent His bundle pacing: Electrophysiological and echocardiographic observations from long-term follow-up. Pacing Clin Electrophysiol. 2017;40(7):883-91.

10. Su L, Xu L, Wu SJ, Huang WJ. Pacing and sensing optimization of permanent His-bundle pacing in cardiac resynchronization therapy/implantable cardioverter defibrillators patients: value of integrated bipolar configuration. Europace. 2016;18(9):1399-405.

11. Padala SK, Ellenbogen KA, Koneru JN. Intermittent loss of capture in a His bundle pacemaker: What is the cause? HeartRhythm Cáse Rep. 2017;3(11):555-8.

12. Vijayaraman $\mathrm{P}$, Ellenbogen KA. Approach to permanent His bundle pacing in challenging implants. Heart rhythm. 2018.

13. Ajijola OA, Upadhyay GA, Macias C, Shivkumar K, Tung R. Permanent His-bundle pacing for cardiac resynchronization therapy: Initial feasibility study in lieu of left ventricular lead. Heart Rhythm. 2017;14(9):1353-61.

14. Vijayaraman P, Naperkowski A, Subzposh FA, Abdelrahman M, Sharma PS, Oren JW, et al. Permanent His-bundle pacing: Long-term lead performance and clinical outcomes. Heart Rhythm. 2018;15(5):696-702.

15. Zhang J, Guo J, Hou X, Wang Y, Qian Z, Li K, et al. Comparison of the effects of selective and nonselective His bundle pacing on cardiac electrical and mechanical synchrony. Europace. 2018;20(6):10107.

16. Abdelrahman M, Subzposh FA, Beer D, Durr B, Naperkowski A, Sun $\mathrm{H}$, et al. Clinical Outcomes of His Bundle Pacing Compared to Right Ventricular Pacing. J Am Coll Cardiol. 2018;71(20):2319-30. 
17. Ye $Y$, Zhang $Z$, Sheng $X$, Wang $B$, Chen $S$, Pan $Y$, et al. Upgrade to his bundle pacing in pacingdependent patients referred for pulse generator change: Feasibility and intermediate term follow up. Int J Cardiol. 2018;260:88-92.

18. Shan P, Su L, Zhou X, Wu S, Xu L, Xiao F, et al. Beneficial effects of upgrading to His bundle pacing in chronically paced patients with left ventricular ejection fraction $<50$. Heart Rhythm. 2018;15(3):405-12.

19. Narula OS. Longitudinal dissociation in the His bundle. Bundle branch block due to asynchronous conduction within the His bundle in man. Circulation. 1977;56(6):996-1006.

20. Sharma PS, Ellison K, Patel HN, Trohman RG. Overcoming left bundle branch block by permanent His bundle pacing: Evidence of longitudinal dissociation in the His via recordings from a permanent pacing lead. HeartRhythm Case Rep. 2017;3(11):499-502.

21. Abraham WT, Fisher WG, Smith AL, Delurgio DB, Leon AR, Loh E, et al. Cardiac resynchronization in chronic heart failure. N Engl J Med. 2002;346(24):1845-53.

22. Cleland JG, Daubert JC, Erdmann E, Freemantle N, Gras D, Kappenberger L, et al. The effect of cardiac resynchronization on morbidity and mortality in heart failure. N EngI J Med. 2005;352(15):153949.

23. Barold SS, Herweg B. Cardiac Resynchronization in Patients with Atrial Fibrillation. J Atr Fibrillation. 2015;8(4):1383.

24. Linde C. When cardiac resynchronization therapy may be harmful: time to wake up. Europace. 2015;17(2):171-3.

25. Shah RM, Patel D, Molnar J, Ellenbogen KA, Koneru JN. Cardiac-resynchronization therapy in patients with systolic heart failure and QRS interval $</=130 \mathrm{~ms}$ : insights from a meta-analysis. Europace. 2015;17(2):267-73.

26. Ruschitzka F, Abraham WT, Singh JP, Bax JJ, Borer JS, Brugada J, et al. Cardiac-resynchronization therapy in heart failure with a narrow QRS complex. N Engl J Med. 2013;369(15):1395-405.

27. Thibault B, Harel F, Ducharme A, White M, Ellenbogen KA, Frasure-Smith N, et al. Cardiac resynchronization therapy in patients with heart failure and a QRS complex $<120$ milliseconds: the Evaluation of Resynchronization Therapy for Heart Failure (LESSER-EARTH) trial. Circulation. 2013;127(8):873-81.

28. Curtis AB, Worley SJ, Adamson PB, Chung ES, Niazi I, Sherfesee L, et al. Biventricular pacing for atrioventricular block and systolic dysfunction. N Engl J Med. 2013;368(17):1585-93.

29. Funck RC, Blanc JJ, Mueller HH, Schade-Brittinger C, Bailleul C, Maisch B, et al. Biventricular stimulation to prevent cardiac desynchronization: rationale, design, and endpoints of the 'Biventricular Pacing for Atrioventricular Block to Prevent Cardiac Desynchronization (BioPace)' study. Europace. 2006;8(8):629-35.

30. Huang WA, Wassie MA, Ajijola OA. Permanent His Bundle Pacing for Cardiac Resynchronization. Curr Treat Options Cardiovasc Med. 2018;20(3):23.

31. Sharma PS, Dandamudi G, Herweg B, Wilson D, Singh R, Naperkowski A, et al. Permanent Hisbundle pacing as an alternative to biventricular pacing for cardiac resynchronization therapy: $A$ multicenter experience. Heart Rhythm. 2018;15(3):413-20.

32. Huang W, Su L, Wu S, Xu L, Xiao F, Zhou X, et al. Long-term outcomes of His bundle pacing in patients with heart failure with left bundle branch block. Heart. 2018.

33. Sharma PS, Naperkowski A, Bauch TD, Chan JY, Arnold AD, Whinnett ZI, et al. Permanent His Bundle Pacing for Cardiac Resynchronization Therapy in Patients With Heart Failure and Right Bundle Branch Block. 2018;11(9):e006613.

34. His Bundle Pacing Versus Coronary Sinus Pacing for Cardiac Resynchronization Therapy. (HisSYNC). Retrieved from https://clinicaltrials.gov/ct2 (Identification No. NCT02700425). 
35. The His Optimised Pacing Evaluated for Heart Failure Trial (HOPE-HF). (HOPE-HF). Retrieved from https://clinicaltrials.gov/ct2 (Identification No. NCT02671903).

36. Comparison of His Bundle Pacing and Bi-Ventricular Pacing in Heart Failure With Atrial Fibrillation. Retrieved from https://clinicaltrials.gov/ct2 (Identification No. NCT02805465).

37. Huang W, Su L, Wu S, Xu L, Xiao F, Zhou X, et al. A Novel Pacing Strategy With Low and Stable Output: Pacing the Left Bundle Branch Immediately Beyond the Conduction Block. Can J Cardiol. 2017;33(12):1736 e1- e3.

38. Huang W, Su L, Wu S, Xu L, Xiao F, Zhou X, et al. Benefits of Permanent His Bundle Pacing Combined With Atrioventricular Node Ablation in Atrial Fibrillation Patients With Heart Failure With Both Preserved and Reduced Left Ventricular Ejection Fraction. J Am Heart Assoc. 2017;6(4).

39. Vijayaraman P, Subzposh FA, Naperkowski A. Atrioventricular node ablation and His bundle pacing. Europace. 2017;19(suppl_4):iv10-iv6.

40. Catanzariti D, Maines M, Cemin C, Broso G, Marotta T, Vergara G. Permanent direct his bundle pacing does not induce ventricular dyssynchrony unlike conventional right ventricular apical pacing. An intrapatient acute comparison study. J Interv Card Electrophysiol. 2006;16(2):81-92.

41. Zanon F, Bacchiega E, Rampin L, Aggio S, Baracca E, Pastore G, et al. Direct His bundle pacing preserves coronary perfusion compared with right ventricular apical pacing: a prospective, cross-over mid-term study. Europace. 2008;10(5):580-7.

42. Kronborg MB, Mortensen PT, Gerdes JC, Jensen HK, Nielsen JC. His and para-His pacing in AV block: feasibility and electrocardiographic findings. J Interv Card Electrophysiol. 2011;31(3):255-62.

43. Catanzariti D, Maines M, Manica A, Angheben C, Varbaro A, Vergara G. Permanent His-bundle pacing maintains long-term ventricular synchrony and left ventricular performance, unlike conventional right ventricular apical pacing. Europace. 2013;15(4):546-53.

44. Pastore G, Aggio S, Baracca E, Fraccaro C, Picariello C, Roncon L, et al. Hisian area and right ventricular apical pacing differently affect left atrial function: an intra-patients evaluation. Europace. 2014;16(7):1033-9.

45. Barba-Pichardo R, Manovel Sanchez A, Fernandez-Gomez JM, Morina-Vazquez P, VenegasGamero J, Herrera-Carranza M. Ventricular resynchronization therapy by direct His-bundle pacing using an internal cardioverter defibrillator. Europace. 2013;15(1):83-8.

46. Lustgarten DL, Crespo EM, Arkhipova-Jenkins I, Lobel R, Winget J, Koehler J, et al. His-bundle pacing versus biventricular pacing in cardiac resynchronization therapy patients: A crossover design comparison. Heart Rhythm. 2015;12(7):1548-57.

47. Vijayaraman P, Dandamudi G, Herweg B, Sharma P, Ellenbogen K. Permanent His Bundle pacing is an excellent alternative to cardiac resynchronization therapy. Heart Rhythm. 2016;13(5):S39-S40.

Figure legend: 


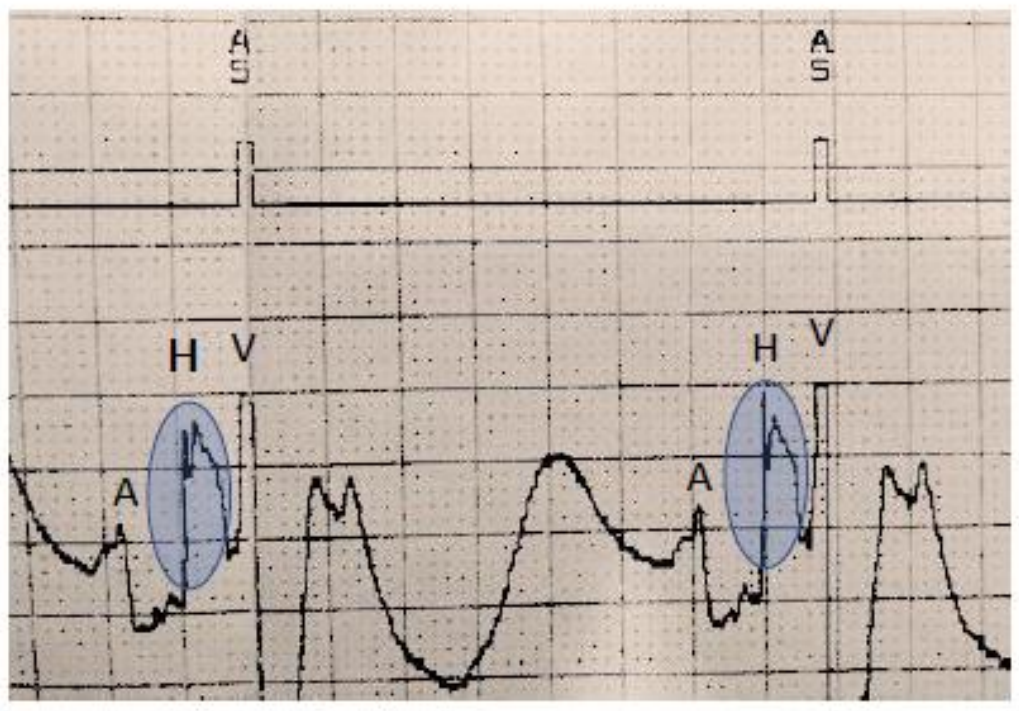

1. During implantation of a CIED, a His bundle lead is affixed into the tissue where a large His bundle electrogram (Egm) is recorded. The lead is connected in a unipolar fashion to the pacing system analyzer (PSA) during the procedure. Due to the annular location of the lead, a far field atrial $\operatorname{Egm}(A)$, a near field His Egm $(H)$, and a ventricular egm $(V)$ are recorded from the lead tip. The highlighted area depicts His bundle current of injury. AS represents ventricular sensing- the lead tip is connected to the atrial channel for better sensing (atrial channel settings are better optimized for sensing during His bundle implants through the Medtronic PSA). 

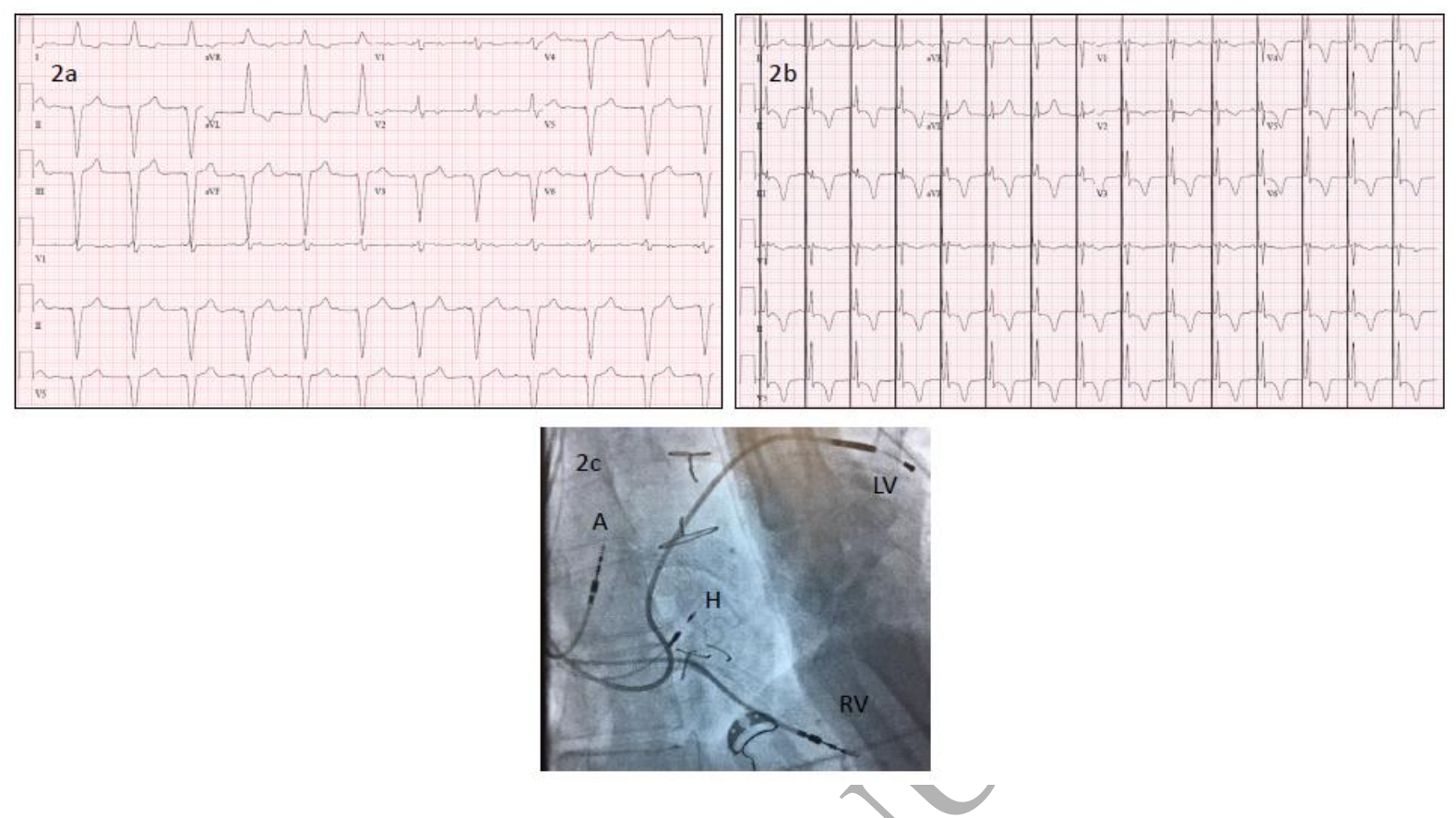

2. A 54-year old female with Tetralogy of Fallot repair at a young age subsequently developed multiple atrial arrhythmias. After several ablations to treat her atrial arrhythmias, she underwent atrioventricular nodal ablation followed by CRT-P implantation. Pacing thresholds increased along with phrenic nerve capture and the lead was subsequently abandoned. Patient developed HF symptoms and LV EF reduced from $54 \%$ to $35 \%$ with RV pacing. Figure $2 \mathrm{a}$ demonstrates an atrial tachycardia with RV pacing. She underwent successful His bundle pacing 3 years later. This resulted in selective His bundle capture (2b). Note the isoelectric segments between the pacing stimulus to the QRS onset indicating recruitment of His bundle alone without any local ventricular fusion. Also, there are diffuse $T$ wave changes related to $T$ wave memory which normalize within a few weeks. The CXR displays atrial (A) and left ventricular (LV) leads that were abandoned (2c). A dual chamber was used in this case with the His lead plugged into the atrial port and the old RV lead plugged into the RV port. The device was programmed in the DVIR mode (RV lead acts as a back-up lead only in this mode). Her LV EF normalized in 3 months. 

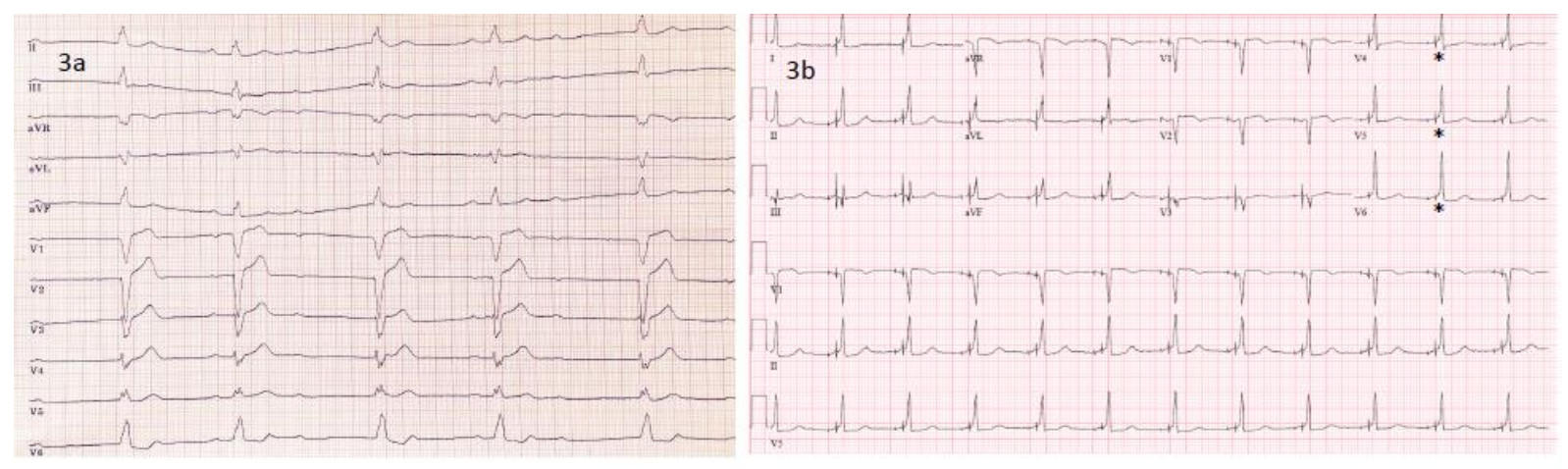

3. A 62-year old female presented with heart block and sudden cardiac arrest and underwent implantation of a dual chamber ICD. She developed HF symptoms over the next year and her LV EF reduced from $55 \%$ to $30 \%$. She consented to undergoing HBP. Baseline ECG demonstrates underlying high degree heart block and wide LBBB (3a). Non-selective His bundle pacing was successfully achieved. Asterisk $\left({ }^{*}\right)$ denotes fusion between His bundle pacing and minimal local ventricular capture (pseudo delta wave). Her EF normalized in 4 months with resolution of HF symptoms. 

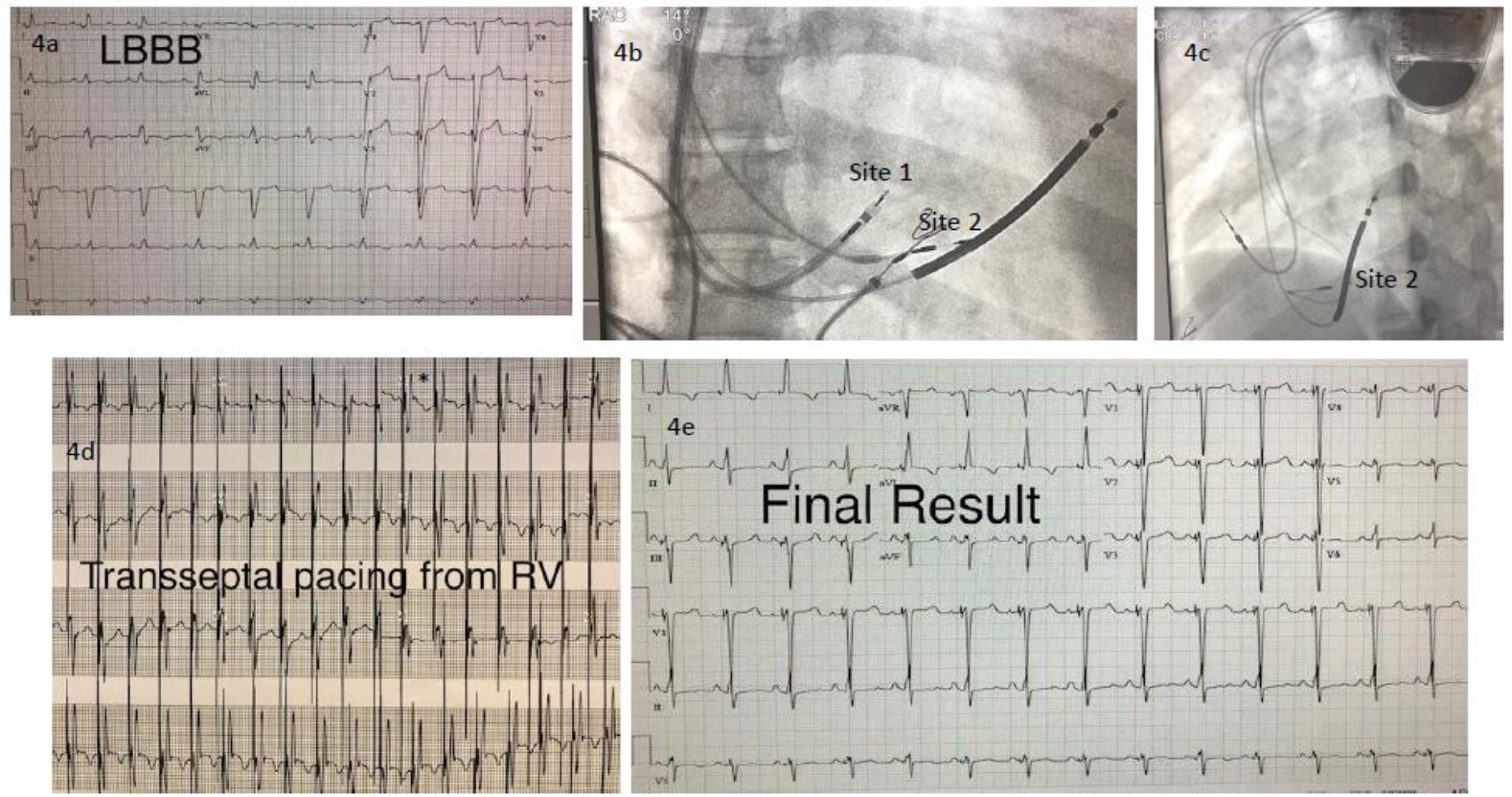

4. A 44-year old female with non-ischemic cardiomyopathy, LBBB and NYHA class III HF symptoms was referred for His bundle pacing due to failed LV lead placement (4a). During implant, LBBB was completely recruited at/above $4 \mathrm{~V} @ 1 \mathrm{~ms}$. Due to high pacing thresholds, trans-septal pacing was attempted. CXR shows the lead placement ( $4 b$ \& $4 c)$. Site 1 is where LBBB recruitment was obtained at high pacing threshold. Site 2 is past the tricuspid annulus and the lead is screwed deep into the septum until pacing reveals a RBBB pattern in V1 $\left({ }^{*}\right)$, suggestive of direct LBB pacing (4d). With AV delays adjusted to allow for RBB conduction, the fused QRS is narrow with $\mathrm{QRS}<120 \mathrm{~ms}(4 \mathrm{e})$. 
Table 1: His Bundle Pacing versus Right Ventricular Pacing

\begin{tabular}{|c|c|c|c|c|}
\hline Study & Patient population & Study design & $\mathrm{N}$ & Findings \\
\hline $\begin{array}{l}\text { Catanzariti et } \\
\text { al. (2006) (40) }\end{array}$ & $\begin{array}{l}\text { Patients with tachy-brady } \\
\text { syndrome or supra-Hisian } \\
\text { AV block }\end{array}$ & Comparative & 24 & $\begin{array}{l}\text { Improvement in ventricular dyssynchrony, mitral } \\
\text { regurgitation and left ventricular systolic } \\
\text { function, Tei index }(\mathrm{p}<0.05) \text { with HBP as } \\
\text { compared to RVP. }\end{array}$ \\
\hline $\begin{array}{l}\text { Zanon et al. } \\
(2008)(41)\end{array}$ & $\begin{array}{l}\text { Patients with standard } \\
\text { pacemaker indication }\end{array}$ & $\begin{array}{c}\text { Crossover study } \\
\text { design }\end{array}$ & 12 & $\begin{array}{l}\text { Better perfusion score with HBP than } \\
\text { with RVP }(0.44 \pm 0.5 \text { vs } 0.71 \pm 0.53 \\
\text { respectively; } p=0.011)\end{array}$ \\
\hline $\begin{array}{l}\text { Kronborg et. } \\
\text { al (2011) (42) }\end{array}$ & $\begin{array}{l}\text { Patients with pacemaker } \\
\text { indication due to AV } \\
\text { block, } \mathrm{LVEF}>0.4, \mathrm{QRS} \\
\text { duration }<120 \mathrm{~ms} \text { and } \\
\text { sinus rhythm }\end{array}$ & Comparative & 38 & $\begin{array}{l}\text { Mean QRS duration was } 153 \pm 12 \text { ms with mid- } \\
\text { septal pacing vs } 161 \pm 15 \mathrm{~ms} \text { with apical pacing. }\end{array}$ \\
\hline $\begin{array}{l}\text { Catanzariti et } \\
\text { al. (2013) (43) }\end{array}$ & $\begin{array}{l}\text { Patients with standard } \\
\text { pacemaker indication }\end{array}$ & $\begin{array}{l}\text { Prospective } \\
\text { cohort }\end{array}$ & 26 & $\begin{array}{l}\text { Decreased EF }(50.1 \pm 8.8 \% \text { versus } 57.3 \pm 8.5 \% \\
\mathrm{p}<0.001) ; \text { increased MR }(22.5 \pm 10.9 \% \text { vs } \\
16.3 \pm 12.4 \% ; \mathrm{p}=0.018) \text { and worsening } \\
\text { interventricular delay }(33.4 \pm 19.5 \text { ms vs } 7.1 \pm 4.7 \\
\mathrm{ms}, \mathrm{p}=0.003) \text { with RVAP, compared with HBP. }\end{array}$ \\
\hline $\begin{array}{l}\text { Pastore et al. } \\
(2014)(44)\end{array}$ & $\begin{array}{l}\text { Patients with standard } \\
\text { pacemaker indication }\end{array}$ & $\begin{array}{c}\text { Crossover study } \\
\text { design }\end{array}$ & 37 & $\begin{array}{l}\text { Increased left ventricular }(\mathrm{LV}) \text { electromechanical } \\
\text { delay }(\mathrm{p}=0.001) \text { and intra-LV dyssynchrony } \\
(\mathrm{p}=0.001) \text {; increased } \mathrm{LV} \text { isovolumetric } \\
\text { contraction time }(\mathrm{p}=0.001) \text { and } \mathrm{LV} \text { isovolumetric } \\
\text { relaxation time }(\mathrm{p}=0.05) \text {; and decreased LV } \\
\text { ejection time ( } \mathrm{p}=0.033) \text { with RVAP compared to } \\
\text { HBP. }\end{array}$ \\
\hline $\begin{array}{l}\text { Sharma et al. } \\
(2015)(3)\end{array}$ & $\begin{array}{l}\text { Patients receiving } \\
\text { pacemaker for the } \\
\text { prevention or treatment of } \\
\text { bradycardia }\end{array}$ & & 192 & $\begin{array}{l}\text { Similar fluoroscopy times }(12.7 \pm 8 \mathrm{~min} \text { versus } \\
10 \pm 14 \text { min; median } 9.1 \text { versus } 6.4 \mathrm{~min} ; \mathrm{p}=0.14) \\
\text { and higher pacing thresholds in the HBP group } \\
\text { vs the RVP group ( } 1.35 \pm 0.9 \mathrm{~V} \text { vs } 0.6 \pm 0.5 \mathrm{~V} \text { at } \\
0.5 \mathrm{~ms} ; \mathrm{p}<0.001) \text {. Decreased HF hospitalization } \\
\text { in the HBP group vs the RVP group ( } 2 \% \text { versus } \\
15 \% ; \mathrm{p}=0.02 \text { ) with no difference in mortality } \\
\text { between the two groups. }\end{array}$ \\
\hline $\begin{array}{l}\text { Vijayaraman } \\
\text { et al. (2018) } \\
\quad(14)\end{array}$ & $\begin{array}{l}\text { Patients with standard } \\
\text { pacemaker indication }\end{array}$ & $\begin{array}{l}\text { Prospective } \\
\text { cohort }\end{array}$ & 192 & $\begin{array}{l}\text { Unchanged LVEF in the HBP group }(55 \% \pm 8 \% \\
\text { vs } 57 \% \pm 6 \% ; \mathrm{p}=0.13) \text { vs decreased LVEF in the } \\
\text { RVP group }(57 \% \pm 7 \% \text { vs } 52 \% \pm 11 \% ; \mathrm{p}=0.002) \text {, } \\
\text { lower incidence of pacing-induced } \\
\text { cardiomyopathy in the HBP as compared to the } \\
\text { RVP group ( }(2 \% \text { vs } 22 \% \text {; }=0.04) \text {, lower } \\
\text { mortality or HFH with HBP as compared to RVP } \\
\text { with }>40 \% \text { ventricular pacing after } 5 \text { years of } \\
\text { follow up ( } 32 \% \text { vs } 53 \% ; p=0.04) \text {. }\end{array}$ \\
\hline $\begin{array}{l}\text { Abdelrahman } \\
\text { et al. (2018) } \\
\quad(16)\end{array}$ & $\begin{array}{l}\text { Patients with standard } \\
\text { pacemaker indication }\end{array}$ & $\begin{array}{c}\text { Prospective } \\
\text { cohort }\end{array}$ & 765 & $\begin{array}{l}\text { Lower mortality, HFH or upgrade to BiV pacing } \\
\text { with HBP ( } 83 \text { of } 332 \text { patients [ } 25 \%] \text { ) compared } \\
\text { to RVP ( } 137 \text { of } 433 \text { patients [ } 32 \%] \text {; hazard ratio } \\
\text { [HR]: } 0.71 ; 95 \% \text { confidence interval [CI]: } 0.534 \\
\text { to } 0.944 ; p=0.02) \text {. }\end{array}$ \\
\hline
\end{tabular}


Table 2: His Bundle Pacing for Cardiac Resynchronization Therapy

Study

Barba-

Pichardo et al.

(2013) (45)

Lustgarten et

al. (2015) (46)
Patient population

CRT eligible patients with

failed LV lead placement
Findings

\begin{tabular}{c|c|c} 
Study design & $\mathrm{N}$ & Findings \\
\hline Observational & 16 & Improvement in functional clas
\end{tabular}

parameters including mean LVEDD/LVESD

(65.9/55.4 vs 59.5/51.2; $\mathrm{p}<0.01)$, mean LVEF (29 vs 36; $\mathrm{p}<0.05)$, mean QRS (166 vs 97; $\mathrm{p}<0.001$ ).

QRS narrowing in 21 (72\%) patients,

improvement in clinical outcomes (EF, NYHA

class, 6 min-walk and QOL score) for both pacing modes as compared to baseline.

QRS narrowing $(165 \pm 31$ to $115 \pm 19 \mathrm{~ms} ; \mathrm{p}<$

$0.05)$, improvement in mean LVEF $(30 \pm 10$ to 47

$\pm 11 \% ; \mathrm{p}<0.05) \&$ NYHA class (2.9 to 1.6 ; $\mathrm{p}=0.05)$.

Ajijola et al.

(2017) (13)

Sharma et al.

(2018) (31)

Shan et al.

(2018) (18)

(18) induced cardiomyopathy

and CRT non-responders

Patients with CRT
indication or failed BiVP

Observational

study

Observational

21

QRS narrowing ( $180 \pm 23$ to $129 \pm 13 \mathrm{~ms}$;

$\mathrm{p}<0.0001$ ), improvement in NYHA class, LVEF

$(27 \pm 10$ to $41 \pm 13 \% ; \mathrm{p}<0.001) \& \mathrm{LVID}_{\mathrm{d}}(5.4 \pm$ 0.4 to $4.5 \pm 0.3 \mathrm{~cm} ; \mathrm{p}<0.001)$.

QRS narrowing ( $157 \pm 33$ to $117 \pm 18 \mathrm{~ms}$;

$\mathrm{p}=0.0001)$, improvement in LVEF ( $30 \pm 10$ to 43

$\pm 13 \% ; \mathrm{p}=0.0001) \&$ NYHA class $(2.8 \pm 0.5$ to $1.8 \pm 0.6 ; \mathrm{p}=0.0001)$.

18 QRS narrowing (156.9 \pm 21.7 to $107.1 \pm 16.5 \mathrm{~ms}$; $\mathrm{p}<0.01)$, improvement in LVEF $(35.7 \pm 7.9 \%$ to $52.8 \pm 9.6 \%$; $<<0.01) \&$ left ventricular enddiastolic dimensions $(62.3 \pm 6.9$ to $55.5 \pm 7.7 \mathrm{~mm}$; $\mathrm{p}<0.01)$.

Huang et al

(2018) (32)

Patients with LBBB and

Observational study

Acute LBBB correction in $72(97.3 \%)$ patients, improvement in LVEF $(32.4 \pm 8.9 \%$ to $55.9 \pm 10.7 \% ; \mathrm{p}<0.001)$, LVESV $(137.9 \pm 64.1 \mathrm{~mL}$ to $52.4 \pm 32.6 \mathrm{~mL} ; \mathrm{p}<0.001) \&$ NYHA Class $(2.73 \pm 0.58$ to $1.03 \pm 0.18 ; \mathrm{p}<0.001)$.

Sharma et al. (2018) (33)

\section{Patients with RBBB and} heart failure

\section{Observational} study
Successful HBP in 37 of 39 patients (95\%) with QRS narrowing ( $158 \pm 24$ to $127 \pm 17 \mathrm{~ms}$; $\mathrm{p}=0.0001)$, improvement in LVEF $(31 \pm 10 \%$ to $39 \pm 13 \% ; \mathrm{p}=0.004) \&$ NYHA Class $(2.8 \pm 0.6$ to $2 \pm 0.7 ; \mathrm{p}=0.0001)$. 